\title{
Pulmonary valve cusp augmentation with autologous pericardium may improve early outcome for tetralogy of Fallot
}

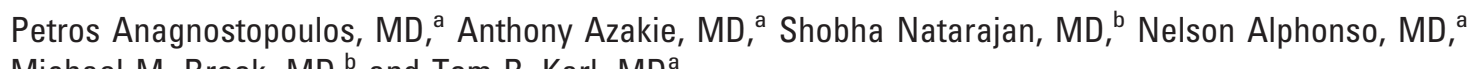
Michael M. Brook, MD, and Tom R. Karl, MD ${ }^{a}$

Objectives: The transannular patch used to relieve right ventricular outflow tract obstruction in children with tetralogy of Fallot may result in pulmonary insufficiency. We hypothesized that pulmonary valve cusp augmentation with pericardium would decrease pulmonary insufficiency and improve the early outcome for transatrialtranspulmonary tetralogy of Fallot repair requiring transannular patch.

Methods: Since November 2001, 41 patients with tetralogy of Fallot and 2 patients with isolated pulmonary valve stenosis had relief of right ventricular outflow tract obstruction with either a transannular patch plus pulmonary valve cusp augmentation $(\mathrm{n}=18)$ or a transannular patch alone $(\mathrm{n}=25)$. Data were retrospectively collected.

Results: The median age (5.3 vs 3.2 months; $P=.09$ ) and weight (6.4 vs $5.2 \mathrm{~kg}$; $P=.3$ ) were similar for the cusp augmentation and transannular patch groups, respectively. The diameter of the pulmonary valve annulus $(6.4$ vs $6.0 \mathrm{~mm} ; P=.57)$ and the McGoon index (1.47 vs $1.69, P=.75$ ) were also similar. The mean aortic clamp time (48 \pm 18 minutes vs $52 \pm 19$ minutes; $P=.46)$ and median cardiopulmonary bypass time ( 89 vs 91 minutes; $P=.9$ ) did not differ. One patient with a transannular patch died of multiorgan system failure. Patients with a pulmonary valve cusp augmentation had a shorter duration of intubation (1 vs 3 days; $P$ $<.001)$ and intensive care unit stay ( 2 vs 8 days; $P<.001)$. Thirteen patients with a transannular patch and 1 patient with a pulmonary valve cusp augmentation required inotropic support for more than 72 hours $(P=.001)$. Discharge echocar-

From the Divisions of Pediatric Cardiac Surgery a and Pediatric Cardiology, ${ }^{\mathrm{b}}$ Pediatric Heart Center, University of California at San Francisco Children's Hospital, San Francisco, Calif.

Read at the Eighty-sixth Annual Meeting of The American Association for Thoracic Surgery, Philadelphia, Pa, April 29-May 3, 2006.

Received for publication April 21, 2006; revisions received Sept 23, 2006; accepted for publication Oct 9, 2006.

Address for reprints: Tom R. Karl, MD, UCSF Department of Surgery, Division of Pediatric Cardiothoracic Surgery, 513 Parnassus Avenue, Suite S-549, Box 0117, San Francisco, CA 94143-0117 (E-mail: karlt@ surgery.ucsf.edu).

J Thorac Cardiovasc Surg 2007;133:640-7

$0022-5223 / \$ 32.00$

Copyright $\odot 2007$ by The American Association for Thoracic Surgery

doi:10.1016/j.jtcvs.2006.10.039 diograms demonstrated moderate or severe pulmonary insufficiency in 5 patients with a pulmonary valve cusp augmentation and in 21 patients with a transannular patch $(P<.001)$. At 7.5 months, 3 patients $(17 \%)$ with a pulmonary valve cusp augmentation had progression of pulmonary insufficiency.

Conclusions: Augmentation of a pulmonary valve cusp reduces the incidence of clinically significant postoperative pulmonary insufficiency. This technique may improve the early outcome for children with tetralogy of Fallot requiring a transannular patch.

$\mathrm{T}$ he combination of a ventriculotomy and free pulmonary insufficiency (PI), both associated with the transannular patch, is implicated in the deterioration of right ventricular function and the development of arrhythmias after tetralogy of Fallot (TOF) repair. In the current era, in which the immediate outcome of TOF repair is expected to be excellent irrespective of surgical technique and timing of the repair, the goal of the surgical treatment of TOF should be the avoidance of long-term complications and a low probability of early and late reoperations. At the University of California at San Francisco (UCSF), since November of 2001, we have used the transatrial-transpulmonary approach for repair 


\author{
Abbreviations and Acronyms \\ ICU = intensive care unit \\ PI = pulmonary insufficiency \\ RVOT $=$ right ventricular outflow tract \\ $\mathrm{TOF}=$ tetralogy of Fallot \\ $\mathrm{UCSF}=$ University of California at San Francisco
}

of TOF to avoid an extensive right ventriculotomy. ${ }^{1,2}$ In the subset of patients who did not have adequate relief of the right ventricular outflow tract (RVOT) obstruction with complete sparing of the pulmonary valve, we extended the pulmonary artery incision for approximately 10 to $15 \mathrm{~mm}$ onto the right ventricular free wall. To further decrease the degree of postoperative PI, we used the technique of augmentation of the native pulmonary valve tissue with autologous pericardium, originally described by Sung and associates. ${ }^{3}$ We hypothesized that it would lead to an improved early outcome for transatrial-transpulmonary TOF repair.

\section{Patients and Methods Patient Population}

The Committee on Human Research at UCSF approved the study.

The study population consisted of all patients with TOF $(\mathrm{n}=$ $41)$ or isolated pulmonary valve stenosis $(n=2)$ who underwent transatrial-transpulmonary repair at UCSF Children's Hospital between November 2001 and August 2005 and required division of the pulmonary valve annulus for adequate relief of RVOT obstruction. Patients with TOF who had repair without division of the pulmonary annulus (pulmonary valve-sparing operation) were excluded, as were those with discontinuous pulmonary arteries, pulmonary atresia and ventricular septal defect, atrioventricular septal defect, and absent pulmonary valve syndrome. Eighteen patients had pulmonary valve cusp augmentation with an autologous pericardial patch according to the technique described by Sung and associates. ${ }^{3}$ During the same period of time, 25 patients underwent repair with a transannular patch and were used as controls. The patients were not randomized, and each of the 2 primary surgeons in the study used both techniques. There was not a clearly defined indication for one procedure or the other.

\section{Operative Details}

The operative technique is outlined in Figure 1. A patch of autologous pericardium was harvested and treated with $0.2 \%$ glutaraldehyde for 10 minutes. Cardiopulmonary bypass was established through bicaval and aortic cannulation. Systemic to pulmonary artery shunts, if present, were ligated after the beginning of cardiopulmonary bypass. Moderate hypothermia was used $\left(28^{\circ} \mathrm{C}\right.$ $32^{\circ} \mathrm{C}$ ). The heart was arrested with antegrade cold blood cardioplegia. The right atrium was opened longitudinally, and the left heart was vented through the foramen ovale. A longitudinal incision was made in the main pulmonary artery and extended to the annulus of the pulmonary valve. The valve was inspected. If there was significant commissural fusion or tethering of the leaflets to the pulmonary artery wall, these were sharply divided. Excision of the parietal extension of the infundibular septum was performed through the tricuspid valve. Hegar dilators were then passed through the tricuspid valve toward the main pulmonary artery. If the diameter of the annulus was more than 2 standard deviations $(z$ score $<-2$ ) below the normal predicted annulus diameter for the patient's weight, the pulmonary annulus was divided. ${ }^{4}$ In the majority of cases the pulmonary valve was bicuspid with location of the commissures at the 3 and 9 o'clock positions. An incision was made in the middle of the anterior cusp and then extended to the right ventricular free wall for approximately 10 to $15 \mathrm{~mm}$. When the pulmonary valve commissures were located at the 6 and 12 o'clock positions or the commissures were anterior and posterior but located off the midline, we divided the pulmonary valve at or near the anterior commissure to preserve as much valve tissue as possible, as described by Sung and associates. ${ }^{3}$ The division of the remaining obstructing muscular and fibrous bands was performed through the ventriculotomy. The ventricular septal defect was closed through the tricuspid valve. The foramen ovale was closed with a temporary purse string suture, the heart was de-aired, and the aortic clamp was removed.

Reconstruction of the RVOT was then performed. In patients who underwent RVOT reconstruction with a transannular patch, the RVOT and pulmonary arteriotomy were closed with an appropriately sized single pericardial or polytetrafluoroethylene (Gore-Tex, WL Gore and Associates, Flagstaff, Ariz) patch. In patients who underwent the transannular patch plus reconstruction with the pulmonary valve cusp augmentation technique, a triangular glutaraldehydetreated autologous pericardial patch was sutured in the endocardium from the most inferior aspect of the right ventriculotomy all the way up to the hinge point of the anterior cusp and then along the divided edge of the valve on either side. When the anterior cusp was small or the anterior commissure was located at the 12 o'clock position, the patch was anchored to the main pulmonary artery. In patients in whom the commissure was eccentric, the patch was sewn to the main pulmonary artery on 1 side and to the free edge of the leaflet on the other side. Then a second patch was used to close the RVOT and the pulmonary arteriotomy, thus recreating a sinus over the augmented valve leaflet.

\section{Clinical Data}

The medical records of all patients were reviewed. We recorded demographic data, previous operations, catheterization procedures, and associated comorbidities, including genetic syndromes. For each patient we gathered data on the operative repair including cardiopulmonary bypass time, aortic clamp time, description of the RVOT management, and additional surgical procedures performed. The postoperative course was then reviewed. The date of extubation, the date of discharge from the intensive care unit (ICU), and the date of discharge from the hospital were used to calculate days intubated, days in the ICU, and days hospitalized. All of the complications were recorded. Finally, the condition during the last clinic visit of the patients with a pulmonary valve cusp augmentation was recorded. Late complications, follow-up interventions, and reoperations were noted.

\section{Echocardiographic Data}

All preoperative and postoperative echocardiograms and echocardiographic reports were reviewed. The preoperative pulmonary 


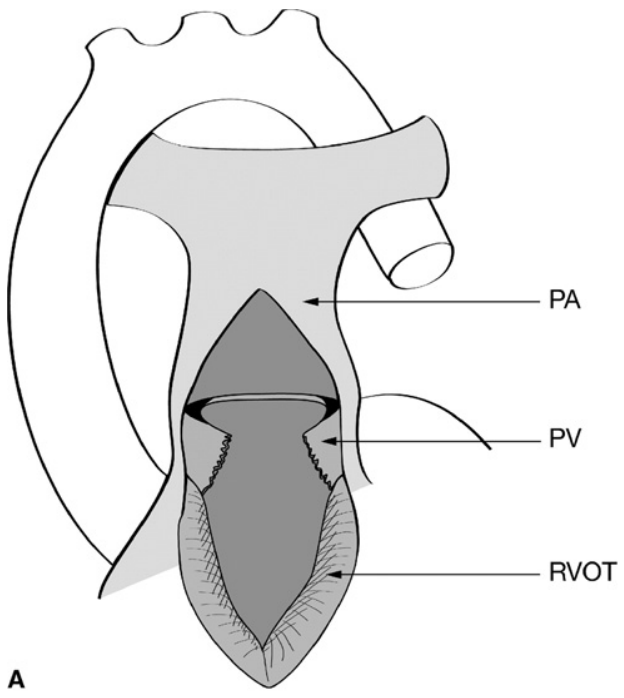

A

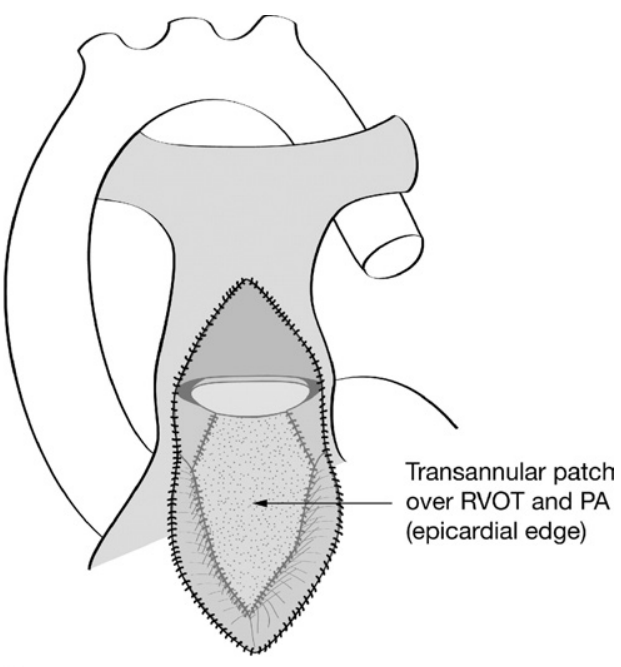

C
Figure 1. A, Pulmonary cusp augmentation repair technique. A transannular incision has been created according to calibration of the RVOT diameter (see text). The incision divides the anterior pulmonary valve leaflet, although the exact location will vary with the valve orientation and morphology. B, Pulmonary cusp augmentation repair technique. A triangular patch of glutaraldehyde-preserved autologous pericardium is sutured to the epicardial edge of the RVOT incision and to the divided edges of the valve leaflet. The leaflet dimensions are based on the caliber of a normal pulmonary valve diameter and should provide sufficient free edge diameter to ensure coaptation with the native valve remnant. C, Pulmonary cusp augmentation repair technique. $A$ second larger oval patch of the same material is sutured to the epicardial aspect of the RVOT incision and to the edges of the pulmonary arteriotomy, creating a sinus anterior to the reconstructed leaflet. $P A$, Pulmonary artery; $P V$, pulmonary valve; RVOT, right ventricular outflow tract. valve annulus was measured in a modified parasternal long-axis view. The branch pulmonary artery diameter was measured in the parasternal short-axis plane, and the McGoon index was calculated. Tricuspid regurgitation was graded as follows: $0=$ none; $1=$ trivial; $2=$ mild; $3=$ moderate $4=$ severe. PI severity was graded in a similar fashion. Patients with mild or less insufficiency were grouped and compared with those with moderate or severe insufficiency. For the patients who underwent pulmonary valve cusp augmentation with autologous pericardium, we reviewed the follow-up echocardiogram to investigate whether there was progression in the degree of PI.

\section{Statistical Analysis}

Variables with a normal distribution are expressed as the mean \pm standard deviation. Variables without a normal distribution are expressed as median and range. Differences were examined for significance by univariate analysis (Student $t$ test, chi-square test, Fisher exact test, or Mann-Whitney $U$ test as appropriate). All data were analyzed with Statistica 6.0 (StatSoft Inc, Tulsa, Okla).

\section{Results}

Patient characteristics and preoperative transthoracic echocardiographic data are shown in Tables 1 and 2, respectively.

Mean aortic clamp time $(48 \pm 18$ minutes vs $52 \pm 19$ minutes for transannular patch; $P=.46$ ) and median cardiopulmonary bypass time ( 89 minutes vs 91 minutes for transannular patch; $P=.9$ ) were similar in the 2 groups. One patient with a transannular patch died. The patient was a 34-week gestational age twin baby boy who never left the hospital after birth and underwent operation at 6 weeks of age. Postoperatively he required extracorporeal membrane oxygenation twice for persistent low cardiac output from right ventricular diastolic dysfunction and intractable atrial tachyarrhythmias. Persistent large output bilateral chylothoraces and acute renal failure developed in the boy, which were treated with peritoneal dialysis. After a brief period of improvement, Staphylococcus epidermidis endocarditis de- 
TABLE 1. Patient characteristics

\begin{tabular}{|c|c|c|c|}
\hline Patient characteristics & $\begin{array}{c}\text { TAP + PV valve } \\
\text { cusp augmentation } \\
n=18\end{array}$ & $\begin{array}{c}\text { TAP } \\
n=25\end{array}$ & $\boldsymbol{P}$ \\
\hline Male:female & $7: 11$ & $12: 13$ & .55 \\
\hline${ }^{*}$ Age (mo) & $5.3(1.3-9.1)$ & $3.2(1.5-62.5)$ & .09 \\
\hline *Weight $(\mathrm{kg})$ & $6.4(2.9-9.1)$ & $5.2(3.3-14.3)$ & .3 \\
\hline Previous modified BT shunt & $3(16 \%)$ & $3(12 \%)$ & \\
\hline Previous balloon valvotomy & 1 & 1 & \\
\hline \multicolumn{4}{|l|}{ Additional diagnosis } \\
\hline Right aortic arch & & 2 & \\
\hline Bilateral SVC & & 1 & \\
\hline PDA & 1 & 4 & \\
\hline Eccentric origin RCA & 1 & & \\
\hline Noonan's syndrome & 1 & & \\
\hline \multicolumn{4}{|l|}{ Additional operations } \\
\hline Branch PA plasty & $1(5 \%)$ & $4(16 \%)$ & \\
\hline Tricuspid valve repair & 1 & & \\
\hline
\end{tabular}

$\overline{T A P}$, Transannular patch; $B T$, Blalock-Taussig; $S V C$, superior vena cava; $P D A$, patent ductus arteriosus; $R C A$, right coronary artery; $P A$, pulmonary artery; $P V$, pulmonary valve. *Median/range.

veloped that led to multiorgan system failure. He died on postoperative day 86 .

The postoperative course and discharge data in the 2 groups of patients are shown in Table 3 .

Of the 18 patients who underwent pulmonary valve cusp augmentation, 1 was lost to follow-up. Two patients required reintervention. One patient presented to the hospital 3 months postoperatively with a delayed pericardial effusion and required a pericardial window. The cause of this effusion was unclear. The second patient was symptomatic with persistent subvalvar pulmonary stenosis. She underwent operative RVOT muscle bundle resection 2 years after her original repair. This patient had moderate PI at discharge, and the degree of PI did not change during followup. At a median follow-up of 7.5 months (range 0-29 months), 6 of the 17 patients $(35.3 \%)$ had moderate or severe PI at follow-up. Three patients (17\%) who underwent pulmonary valve cusp augmentation had progression of PI when compared with the degree of PI at discharge.

\section{Discussion}

There is a current trend for complete repair of TOF in early infancy. This strategy was first applied in neonates with unacceptable oxygen saturations ${ }^{5-7}$ and has been adopted by some centers as the preferred approach even the for minimally cyanotic neonates. ${ }^{8,9}$ Although primary neonatal repair can be accomplished with excellent early results, it can lead to routine use of a large ventriculotomy and repair with a transannular patch in up to $70 \%$ of patients. In fact, this operation is remarkably similar to the technique described by Lillehei in which ventriculotomy is used for VSD closure in up to $96 \%$ of patients. ${ }^{10}$

The use of a transannular patch may result in free PI, which causes right ventricular dilation that in turn compresses the left ventricle. The functional reserve and myocardial contractility of the right (and possibly left) ventricle decrease. These changes can be detected in experimental models as early as 3 months after the onset of PI. ${ }^{11}$ This physiology is well tolerated in the majority of patients for a prolonged period of time, ${ }^{12-14}$ but some will eventually experience decreased exercise tolerance and progressive right ventricular dilation and failure. ${ }^{15,16}$ The exercise performance and the degree of right ventricular failure correlate with the severity of PI. ${ }^{17,18}$ The chronic volume load to the right ventricle after TOF repair leads to dilation of the ventricle and predisposes the patient to late life-threatening ventricular arrhythmias and sudden death. ${ }^{15,19}$

Several groups have described strategies to limit the size of the right ventriculotomy and reduce the incidence of PI. Valved homografts and xenografts were proposed as the most anatomic and physiologic way to resolve RVOT obstruction, but all will eventually need replacement because of patient growth and conduit deterioration. ${ }^{20}$ The use of a monocusp valve created from pericardium, xenograft valve cusps, fascia lata, autologous pulmonary artery wall, or polytetrafluoroethylene has been shown to decrease shortterm PI. ${ }^{21-23}$ However, even the monocusp has limited durability. Gundry and associates ${ }^{21}$ reported that by 24 months only $14 \%$ of their patients with a homograft monocuspbearing transannular patch had a competent valve despite excellent short-term function. Similarly, in a report from the University of Indiana most of the patients had deterioration of the polytetrafluoroethylene monocusp valve function by 3 years, even though the valve function was still better compared with the free PI experienced by the patients with a transannular patch. ${ }^{22}$ Other groups have abandoned the

TABLE 2. Preoperative transthoracic echocardiographic data

\begin{tabular}{lcc}
\hline Preoperative echocardiographic variable & TAP + PV valve cusp augmentation & TAP \\
Pulmonary annulus size mm (median/range) & $\mathbf{n = 1 8}$ & $\mathbf{n = 2 5}$ \\
Preoperative RVOT gradient (mean/SD) & $6.4 \mathrm{~mm}(4-9)$ & $6.0 \mathrm{~mm}(4.5-11)$ \\
Preoperative McGoon index (median/range) & $78.5 \pm 25 \mathrm{~mm} \mathrm{Hg}$ & $83.3 \pm 21 \mathrm{~mm} \mathrm{Hg}$ \\
\hline
\end{tabular}

$T A P$, Transannular patch; $P V$, pulmonary valve; RVOT, right ventricular outflow tract; $S D$, standard deviation. 
TABLE 3. Postoperative clinical and transthoracic echocardiographic data

\begin{tabular}{|c|c|c|c|}
\hline Variable & $\begin{array}{c}\text { TAP + PV valve cusp augmentation } \\
n=18\end{array}$ & $\begin{array}{c}\text { TAP } \\
n=25\end{array}$ & $P$ \\
\hline Duration of intubation (median/range) & $1 d(1-3)$ & $3 d(1-86)$ & $<.001^{*}$ \\
\hline Reintubations & 0 & $2(8 \%)$ & .33 \\
\hline Pneumonia & $1(5 \%)$ & $3(12 \%)$ & .43 \\
\hline Persistent pleural effusion/chylothorax & $3(16 \%)$ & $11(44 \%)$ & $.05^{*}$ \\
\hline Inotropic support > $72 \mathrm{~h}$ & $1(5 \%)$ & $13(52 \%)$ & $.001^{*}$ \\
\hline SVT & $3(17 \%)$ & $11(44 \%)$ & $.05^{*}$ \\
\hline ICU stay (median/range) & $2 d(1-6)$ & $8 d(2-86)$ & $.001^{*}$ \\
\hline Hospital stay (median/range) & $7.5 \mathrm{~d}(4-20)$ & $10 \mathrm{~d}(6-86)$ & $.08^{*}$ \\
\hline Discharge RVOT gradient (median/range) & $13.5 \mathrm{~mm} \mathrm{Hg}(0-60)$ & $15.5 \mathrm{~mm} \mathrm{Hg}(0-73)$ & .34 \\
\hline Moderate/severe $\mathrm{PI}$ on discharge & $5(27 \%)$ & $21(88 \%)$ & $<.001^{*}$ \\
\hline Moderate/severe TR on discharge & $1(5 \%)$ & $10(40 \%)$ & $.005^{*}$ \\
\hline
\end{tabular}

$T A P$, Transannular patch; SVT, supraventricular arrhythmia; ICU, intensive care unit; RVOT, right ventricular outflow tract; $P I$, pulmonary insufficiency; $T R$, tricuspid regurgitation; $P V$, pulmonary valve.

monocusp because they did not think that it provided a significant advantage for the patient. ${ }^{24}$

The Northwestern University group recommends avoidance of a transannular patch with preservation of the annulus of the pulmonary valve. ${ }^{24}$ They perform transatrial closure of the ventricular septal defect, extensive commissurotomy, transpulmonary, and transatrial RVOT muscle resection, and, when needed, augmentation of the infundibulum with a separate patch that does not cross the annulus. They accept a right ventricular to left ventricular systolic pressure ratio of 0.7 , because their main goal is to preserve the annulus, more so than the valve cusps, explaining the $36 \%$ incidence of PI at midterm follow-up. Only 2 of 73 patients who met their criteria required reoperation for residual stenosis at a mean follow-up of approximately 3 years. ${ }^{24}$ In the subgroup of patients who do not have adequate RVOT relief through transatrial and transpulmonary muscle bundle resection, it is not clear that patching of the outflow with preservation of the annulus will offer an advantage in the long run over transannular patching. D'Udekem and associates ${ }^{25}$ reviewed 191 patients who had TOF repair between 1964 and 1984 and concluded that a transannular patch does not result in a worse late functional outcome than patching of an incision limited to the right ventricle.

TOF can be reliably repaired through a transatrial and transpulmonary approach. ${ }^{1,2,26,27}$ This approach differs from the transventricular TOF repair in that the right ventricular incision, if needed, extends just enough to relieve the obstruction of the outflow tract. There is a suggestion that this approach results in a lesser degree of PI, lower incidence of arrhythmias, and better overall right ventricular performance. ${ }^{1,28}$

In our unit since November of 2001, we have used the transatrial-transpulmonary approach for TOF repair, following the policy set forth by Dr Mee at Royal Children's Hospital, Melbourne. Neonates with an unacceptable level of hemoglobin saturation and/or hypercyanotic spells may be palliated with a modified Blalock-Taussig shunt. Although there is documented morbidity and interval mortality with this approach, ${ }^{29}$ there are centers that report excellent outcome and a risk of palliation that approaches $0 \%$ with the use of this strategy. ${ }^{1,24}$ The pros and cons of this approach have been extensively discussed elsewhere and are beyond the scope of the present study. We do make an effort to complete the repair without division of the annulus, although our target right to left ventricular systolic pressure ratio is less than 0.6. If this is not possible we perform a limited ventriculotomy, which is reconstructed with a transannular patch. Since the description of the pulmonary cusp augmentation technique by Sung and associates ${ }^{3}$ in 2003, we have adopted this technique for patients requiring a transannular patch. This technique preserves the native hinge mechanism of the valve cusps, especially when the pulmonary valve is bicuspid and the commissures are located in the 3 and 9 o'clock positions. The use of native valve tissue also offers the theoretic potential of growth. The pulmonary valve cusp augmentation technique effectively reduces the degree of postoperative PI. Of 18 patients who had relief of RVOT obstruction with the use of the pulmonary valve cusp augmentation technique, $5(27 \%)$ had moderate or severe PI at discharge. In contrast, $84 \%$ of the patients with transannular patch reconstruction had clinically significant PI at discharge. In the series published by Sung and associates, ${ }^{3}$ all 18 patients had absent or mild PI at discharge. It is not clear whether the higher incidence of PI in our series is because of technical reasons (ie, a learning curve) or because the patients in Sung's series were older (mean age 13.8 months).

The pulmonary neocusp technique can be used in the majority of patients with TOF and pulmonary stenosis who require division of the pulmonary valve annulus for relief of RVOT obstruction. In our experience it cannot be applied 
only in a certain subgroup of patients who have a small pulmonary annulus with hypoplastic inadequate native pulmonary valve tissue. In this group of patients the transatrialtranspulmonary repair with a minimal right ventriculotomy and closure of the RVOT with a simple transannular patch is our preferred technique.

The acute change from a pressure-loaded to a volumeloaded right ventricle in addition to the right ventriculotomy after a transannular patch reconstruction can adversely affect the performance of the right ventricle in the immediate postoperative period. ${ }^{21,30}$ Our patients who underwent pulmonary valve cusp augmentation had a far better postoperative course when compared with the patients with a transannular patch reconstruction. They stayed intubated for a shorter period of time, required less inotropic support, had fewer persistent pleural effusions and chylothoraces, and had fewer postoperative supraventricular arrhythmias. Turrentine and associates, ${ }^{22}$ using a polytetrafluoroethylene monocusp valve for RVOT reconstruction, effectively decreased the degree of PI compared with their patients who received a nonvalved transannular patch. They also found a significant difference in ICU use and a trend toward better survival in favor of the patients with a monocusp. In contrast, a study from Toronto failed to show any advantage in the postoperative course of patients who had a monocusp valve creation as part of their TOF repair. In this study, however, the degree of postoperative PI was similar in the patients who had a monocusp valve constructed and the patients who underwent transannular patch reconstruction. ${ }^{31}$

Seventeen percent of our patients had progression of PI on short-term follow-up (median 7.5 months). In Sung and colleagues' ${ }^{3}$ series, 2 of the 18 patients also had progression of PI at the 10-month follow-up. We will continue to follow these patients to determine whether this reconstruction is durable or not.

The limitations of the study include its retrospective nonrandomized nature. Although there are no demographic, clinical, and echocardiographic parameters that differed between the 2 groups, it is possible there is selection bias that influenced the results of this study. In addition, although there is a considerable overlap in the use of the 2 techniques in our institution, the majority of the patients who had pulmonary neocusp reconstruction underwent operation after the introduction of the technique by Sung and associates in 2002. ${ }^{3}$ It is possible that part of the improvement in clinical outcome may reflect this time discrepancy. Also, as mentioned above, we have no data on the long-term outcome for these patients or for the durability of the repair, both of which we will assess over time.

Despite all of the limitations of our study, the augmentation of the pulmonary valve cusp with autologous pericardium is simple, does not significantly prolong the operation, reduces the degree of PI in the immediate postoperative period, and improves the early outcome after transatrialtranspulmonary TOF repair requiring a transannular patch. When technically feasible, it has become our preferred technique for RVOT reconstruction in patients with TOF and in patients with pulmonary stenosis who require surgical intervention.

\section{References}

1. Karl TR, Sano S, Pornviliwan S, Mee RB. Tetralogy of Fallot: favorable outcome of nonneonatal transatrial, transpulmonary repair. Ann Thorac Surg. 1992;54:903-7.

2. Pacifico AD, Sand ME, Bargeron LM Jr, Colvin EC. Transatrialtranspulmonary repair of tetralogy of Fallot. J Thorac Cardiovasc Surg. 1987;93:919-24.

3. Sung SC, Kim S, Woo JS, Lee YS. Pulmonic valve annular enlargement with valve repair in tetralogy of Fallot. Ann Thorac Surg. 2003;75:303-5.

4. Rowlatt JF, Rimoldi HJA, Lev M. The quantitative anatomy of the normal child's heart. Pediatr Clin North Am. 1963;10:499-588.

5. Touati GD, Vouhe PR, Amodeo A, Pouard P, Mauriat P, Leca F, et al. Primary repair of tetralogy of Fallot in infancy. J Thorac Cardiovasc Surg. 1990;99:396-402.

6. Di Donato RM, Jonas RA, Lang P, Rome JJ, Mayer JE Jr, Castaneda AR. Neonatal repair of tetralogy of Fallot with and without pulmonary atresia. J Thorac Cardiovasc Surg. 1991;101:126-37.

7. Hirsch JC, Mosca RS, Bove EL. Complete repair of tetralogy of Fallot in the neonate: results in the modern era. Ann Surg. 2000;232:508-14.

8. Reddy VM, Liddicoat JR, McElhinney DB, Brook MM, Stanger P, Hanley FL. Routine primary repair of tetralogy of Fallot in neonates and infants less than three months of age. Ann Thorac Surg. 1995; 60(6 Suppl):S592-6.

9. Parry AJ, McElhinney DB, Kung GC, Reddy VM, Brook MM, Hanley FL. Elective primary repair of acyanotic tetralogy of Fallot in early infancy: overall outcome and impact on the pulmonary valve. J Am Coll Cardiol. 2000;36:2279-83.

10. Lillehei CW, Cohen M, Warden HE, Read RC, Aust JB, Dewall RA, et al. Direct vision intracardiac surgical collection of the tetralogy of Fallot, pentalogy of Fallot, and pulmonary atresia defects; report of first ten cases. Ann Surg. 1955;142:418-42.

11. Kuehne T, Saeed M, Gleason K, Turner D, Teitel D, Higgins CB, et al. Effects of pulmonary insufficiency on biventricular function in the developing heart of growing swine. Circulation. 2003;108:2007-13.

12. Murphy JG, Gersh BJ, Mair DD, Fuster V, McGoon MD, Ilstrup DM, et al. Long-term outcome in patients undergoing surgical repair of tetralogy of Fallot. $N$ Engl J Med. 1993;329:593-9.

13. Bacha EA, Scheule AM, Zurakowski D, Erickson LC, Hung J, Lang P, et al. Long-term results after early primary repair of tetralogy of Fallot. J Thorac Cardiovasc Surg. 2001;122:154-61.

14. Tveter KJ, Foker JE, Moller JH, Ring WS, Lillehei CW, Varco RL. Long-term evaluation of aortic valvotomy for congenital aortic stenosis. Ann Surg. 1987;206:496-503.

15. Nollert GD, Dabritz SH, Schmoeckel M, Vicol C, Reichart B. Risk factors for sudden death after repair of tetralogy of Fallot. Ann Thorac Surg. 2003;76:1901-5.

16. d'Udekem DY, Pasquet A, Lebreux L, Ovaert C, Mascart F, Robert A, et al. Does right ventricular outflow tract damage play a role in the genesis of late right ventricular dilatation after tetralogy of Fallot repair? Ann Thorac Surg. 2003;76:555-61.

17. Singh GK, Greenberg SB, Yap YS, Delany DP, Keeton BR, Monro JL. Right ventricular function and exercise performance late after primary repair of tetralogy of Fallot with the transannular patch in infancy. Am J Cardiol. 1998;81:1378-82.

18. Schamberger MS, Hurwitz RA. Course of right and left ventricular function in patients with pulmonary insufficiency after repair of tetralogy of Fallot. Pediatr Cardiol. 2000;21:244-8.

19. Gatzoulis MA, Till JA, Somerville J, Redington AN. Mechanoelectrical interaction in tetralogy of Fallot. QRS prolongation relates to right 
ventricular size and predicts malignant ventricular arrhythmias and sudden death. Circulation. 1995;92:231-7.

20. Sano S, Karl TR, Mee RB. Extracardiac valved conduits in the pulmonary circuit. Ann Thorac Surg. 1991;52:285-90.

21. Gundry SR, Razzouk AJ, Boskind JF, Bansal R, Bailey LL. Fate of the pericardial monocusp pulmonary valve for right ventricular outflow tract reconstruction. Early function, late failure without obstruction. J Thorac Cardiovasc Surg. 1994;107:908-12.

22. Turrentine MW, McCarthy RP, Vijay P, McConnell KW, Brown JW. PTFE monocusp valve reconstruction of the right ventricular outflow tract. Ann Thorac Surg. 2002;73:871-9.

23. Roughneen PT, DeLeon SY, Parvathaneni S, Cetta F, Eidem B, Vitullo DA. The pericardial membrane pulmonary monocusp: surgical technique and early results. J Card Surg. 1999;14:370-4.

24. Stewart RD, Backer CL, Young L, Mavroudis C. Tetralogy of Fallot: results of a pulmonary valve-sparing strategy. Ann Thorac Surg. 2005; 80:1431-8.

25. d'Udekem Y, Ovaert C, Grandjean F, Gerin V, Cailteux M, ShangoLody P, et al. Tetralogy of Fallot: transannular and right ventricular patching equally affect late functional status. Circulation. 2000; 102(19 Suppl 3):III116-22.

26. Hudspeth AS, Cordell AR, Johnston FR. Transatrial approach to total correction of tetralogy of Fallot. Circulation. 1963;27:796-800.

27. Edmunds LH Jr, Saxena NC, Friedman S, Rashkind WJ, Dodd PF. Transatrial repair of tetralogy of Fallot. Surgery. 1976;80:681-8.

28. Kawashima Y, Kitamura S, Nakano S, Yagihara T. Corrective surgery for tetralogy of Fallot without or with minimal right ventriculotomy and with repair of the pulmonary valve. Circulation. 1981;64(2 Pt 2): II147-53.

29. Gladman G, McCrindle BW, Williams WG, Freedom RM, Benson LN. The modified Blalock-Taussig shunt: clinical impact and morbidity in Fallot's tetralogy in the current era. J Thorac Cardiovasc Surg. 1997; 114:25-30

30. Austen WG, Greenfield LJ, Ebert PA, Morrow AG. Experimental study of right ventricular function after surgical procedures involving the right ventricle and pulmonic valve. Ann Surg. 1962;155: 606-13

31. Bigras JL, Boutin C, McCrindle BW, Rebeyka IM. Short-term effect of monocuspid valves on pulmonary insufficiency and clinical outcome after surgical repair of tetralogy of Fallot. J Thorac Cardiovasc Surg. 1996;112:33-7.

\section{Discussion}

Dr J. Brown (Indianapolis, Ind). We at Indianapolis completely agree with your comments that you should try to reconstruct the pulmonary valve every time you have to cross the annulus. We have used the polytetrafluoroethylene (Gore-Tex; WL Gore and Associates, Flagstaff, Ariz) monocusp.

The illustrations in your presentation look similar to the illustrations of the monocusp with the exception that you sew the edge of your pericardial patch augmentation to the residual cut edges of the leaflet that you cut across. And when your annulus is only 6 $\mathrm{mm}$, and I look at those valves, they're so dysplastic, sewing a pericardial patch to the edges of the leaflets just seems kind of difficult in a 3-, 4-, or 5-month-old child. So I wonder, the patches that you actually sew into these patients must be much wider than the rest of the cusps put together to get an annulus diameter big enough for that child.

When we originally started using polytetrafluoroethylene (Gore-Tex) monocusps, we sewed them to the pulmonary artery wall rather than the residual leaflet tissue. They were big enough to be draped across the back of the RVOT so that it made it a monocusp. How do your patch dimensions compare with our polytetrafluoroethylene (Gore-Tex) monocusps? We know that our polytetrafluoroethylene (Gore-Tex) monocusps last 2 or 3 years, and I am interested to find out whether these pericardial cusp augmentations will last even a longer period of time. So that's the first question. Is there really a difference between your technique and what we've been doing for 10 or 12 years?

Dr Anagnostopoulos. I think the difference is that by suturing the pericardial tissue into the native valve apparatus, we try to use the hinge mechanism of the valve and make it coapt with the rest of the tissue. That cannot be done in the subset of patients in whom the annulus is less than 4 or $5 \mathrm{~mm}$, and in very dysplastic valves. In these patients, the transannular patch is still our technique of choice.

To answer your question, I think, yes, our cusp is bigger than the monocusp, the way I understand it by looking at your illustrations. The monocusp is a technique that we don't use at UCSF. The pericardium is more pliable and gives you more lead to be able to use a wider patch than the traditional monocusp.

Dr Brown. My second question is that at least in people who have used a biologic monocusp, a cusp from a homograft, autologous pericardium, or bovine pericardium, none of them have remained functional after about 3 or 4 months. Your follow-up is 7.5 months, on average, with a follow-up of more than 2 years. Do you think your monocusps for some reason are going to be more durable than those of everybody else who has tried the biologic monocusp?

Dr Anagnostopoulos. The only reason why this could happen, if it does (and as you said, we don't have the data yet), is because it is attached to the valve tissue itself. The theoretic potential of growth of the remaining native valve tissue exists. I think only time will tell.

Dr Brown. About 25 patients, or $27 \%$ of your patients, who had the cusp augmentation had moderate to severe PI. What do those cusps that failed look like? Are they fixed in the open position, as I would expect? Are they still mobile and they just weren't sized right? Why do $25 \%$ of your patients have moderate to severe PI early after operation?

Dr Anagnostopoulos. They are fixed in the open position as you described. This probably represents technical problems with the construction of this pericardial cusp augmentation flap. It mostly happened in the beginning of our experience. Dr Sung, in his article, quotes a similar problem in 2 of his 18 patients. The rate of deterioration in his study was $17 \%$ in 2 years and was $17 \%$ in ours as well. So I think that it had to do with the way we did it, and I think we learned better how to do that as time went by. I don't remember, in the last part of our experience, seeing that problem anymore. That was part of our learning curve with the technique.

Dr Brown. I congratulate you and your group for attempting to reconstruct the pulmonary valve in every transannular patch reconstructive. We totally agree. I think time will only tell whether this biologic cusp augmentation is going to have the same fate that others have or whether it will be better.

Dr Y. Kawashima (Minoo City, Japan). I congratulate Dr Anagnostopoulos and his coauthors for their excellent results of transatrial-transpulmonary repair for patients with TOF, particularly in patients who underwent pulmonary valve augmentation. As you may know, I started this transatrial-transpulmonary repair for TOF in 1978, and I have simultaneously repaired the stenotic pulmonary valve precisely using the cusp augmentation technique with an autologous pericardium when necessary with a method similar to that reported today. 
Recently I reviewed the late result of the initial 110 patients who underwent operation 16 to 28 years ago at the age of 5 years or less. There was 1 operative death, and 1 patient died 18 years after surgery. Among the other 108 patients, followed on an average of 22 years, 8 patients underwent reoperation, 7 for recurrent infundibular stenosis and 1 for calcified annular patch; however, no patient underwent reoperation for pulmonary regurgitation.

I presume this is because of the somewhat functioning repaired valve and a slightly enlarged pulmonary annulus. Excessive enlargement of the pulmonary annulus was not necessary in our series because of the initially functioning pulmonary valve.

I agree with the author's conclusion that pulmonary valve repair using the cusp augmentation technique reduces the incidence of postoperative pulmonary regurgitation, and my conclusion is that precisely performed cusp augmentation reduces pulmonary regurgitation even on an average of 22 years after surgery.

Dr Anagnostopoulos. Thank you for those comments.

Dr M. Wojtalik (Poznan, Poland). According to the drawing you have presented, it seems that there are 2 large patches reconstructing the RVOT, 1 inside creating the cusp and 1 outside. I would be afraid about the creation of the clotting between and obstructing the RVOT. Did you observe such a complication?

Dr Anagnostopoulos. We followed those patients, and at this median follow-up of 8 months we haven't seen any clots. One patient had to undergo reoperation for residual RVOT obstruction, but during the operation it was clear that this was because of the obstructing muscle fibers in the outflow and not because of the cusp obstructing the valve at the valvar level.

Dr S. Bradley (Charleston, SC). What do you and Dr Karl think are the best anatomic selection criteria for using this technique? It sounds like it would be difficult to use with a very small pulmonary valve (a $z$ score of -4 or so) or a stenotic unicusp valve, as opposed to a valve that was mildly stenotic ( $z$ scores of -2 to -3$)$. Is that fair, and do you have those criteria?

Dr Anagnostopoulos. Yes, that's fair. The ideal valve for this technique is one that has the commissures at the 3 and 9 o'clock positions so the anterior leaflet can be bisected in the midline. Those are anything from $50 \%$ to $70 \%$ of the valves, according to Dr Kawashima's study from 1981, and according to Steward and colleagues' series from last year that was presented at the Society of Thoracic Surgeons meeting. So I think it can be done. When the commissures are aligned at the 6 and 12 o'clock positions and you cut through the anterior commissure, there is not a lot of valve to sew and you end up reconstructing the RVOT with what looks more than a monocusp valve. But when you have valves that are oriented at the 3 and 9 o'clock positions, then you can really do it because there is a nice remnant to sew your valve augmentation flap on.

Dr A. Schlichter (Buenos Aires, Argentina). I have a short comment and 1 question:

First, it takes a little longer to apply 2 patches than only 1 . What we do is prepare our patch with untreated pericardium, adapted to the exact size that the patient needs to have the pulmonary artery and annulus enlarged, according to tables and body surface area. Having measured the patient's annulus, a resident produces the monocusp on the patch, and we then suture the patch on the annulus.

Are you taking into consideration the diameter that you need to obtain for the enlarged pulmonary annulus and artery? I am asking this because we are now concerned about long-standing pulmonary valve incompetence, which is in relation to the diameter of the pulmonary artery at the time of its surgical enlargement. If we enlarge it too much, we are probably going to have more PI in the long term and more reoperations for TOF. It has been some time since we changed our policy of wide enlargements, and we now prefer to tailor patches to the patient's needs or even a little smaller. In the long term we think it is better to have a nonsignificant pressure gradient than severe pulmonary valve incompetence.

Dr Anagnostopoulos. When we construct that patch, we have in mind what the pulmonary valve annulus should be for that particular patient. To not prolong the operation, you cannot really have it preformed and suture it on because you have to be able to see the valve. Otherwise you can end up creating technical problems; you can tear those valves that sometimes are dysplastic and very thinned out.

To do that, we snare the patent foramen ovale, and then we do this part of the reconstruction on the beating heart. So even though it may take some more time, at least that's not ischemia time. 